\title{
Oculokinetic perimetry for the assessment of visual fields
}

\author{
B J Clark, C Timms, W A Franks
}

\begin{abstract}
The visual fields of 13 children aged 7 to 16 (mean 10.7 years) were assessed by oculokinetic perimetry (OKP), a technique where the field of vision is tested at reading distance using a simple chart, and the results compared with conventional Goldmann perimetry. Cooperation with testing was greater for OKP than Goldmann perimetry and in some cases OKP was better correlated with clinical findings. The advantages of visual field assessment by OKP for children are the close proximity of observer and child, the absence of the requirement for prolonged fixation, and the inexpensiveness and portability of the testing equipment. The disadvantages are movements of the head, with variability in the distance from the target, and the limitation to the central 25 degrees of the visual field.
\end{abstract}

Assessment of visual fields in children is fraught with problems. Frequently, conventional methods of perimetry seem daunting to a child. If there are difficulties with cooperation unreliable assessments result and even experienced perimetrists may have difficulty in making meaningful assessments. Many tests can only be carried out in suitably equipped departments.

Recently Damato has devised a novel method of assessment of the central 25 degrees of the visual fields that is not reliant on expertise or expensive equipment. ${ }^{1}$ The eye moves around a stationary central target, and this method is referred to as oculokinetic perimetry (OKP). The test chart consists of a white tangent chart with a series of light blue fixation targets numbered from 1 to 100 distributed within 25 degrees around a central black test stimulus. These numbers are placed in 16 meridians at 2.5 to 5.0 degree intervals. The patient fixes on each number in turn and determines whether the central target is also visible. In this way, a map of the central visual field can be recorded by noting those points where the central stimulus is not visible. When the test is completed the record sheet is inverted to render the results comparable with those obtained by conventional perimetry. This method had been found to be reliable both in adult patients with glaucomatous field loss and in patients with a range of neurological diseases. ${ }^{1-3}$

This study has attempted to assess the suitability of this simple method for the examination of the visual fields in school age children with a range of ophthalmic and neurological disorders.

\section{Patients and methods}

Thirteen consecutive children aged 7 to 16 years (mean 10.7 years) who were referred for visual field testing were assessed by Goldmann perimetry by an experienced perimetrist and then by OKP by a previously inexperienced observer who was unaware both of the results of Goldmann perimetry and of any field deficit expected on clinical grounds.

OKP was carried out in a busy clinic setting with no special lighting or equipment. The child was seated $33 \mathrm{~cm}$ from the disposable paper test chart which was pinned to a board at eye level. The test was presented as a game where the child was required to tell the observer of those points where it was possible to see both the number on the chart and the central stationary target dot simultaneously. The child was told that some spots were not meant to be seen and the game was to find which ones. The reliability of answers was checked by covering the central dot with a white card and slowly uncovering it. During this the child was asked to respond the instant the dot became visible. Any position on the chart suspected of giving unreliable results was repeated and checked in this way.

Children wore spectacles for both tests when a refractive error was present.

Each child was examined by an ophthalmologist who had access to the childs' ophthalmic and medical history and who graded the correlation between Goldmann fields, OKP, and clinical findings as good, moderate, or poor.

\section{Results}

The clinical details of the subjects and the results of this study are outlined in the table.

Three children had normal Goldmann fields (cases 5, 10, and 11). These were judged to correlate well with both the OKP fields and the clinical findings. The blind spots were successfully determined for all three children (fig 1). In four children (cases 2, 3, 4, and 13) abnormal Goldmann fields were demonstrated, with a good correlation with the OKP fields and with the expected field defect. In hemianopic defects macular sparing was much better demonstrated by OKP (fig 2).

Two children showed constricted visual fields by Goldmann perimetry (cases 1 and 6), this was consistent with the clinical diagnosis, which was not well demonstrated by OKP. Case 1 showed enlarged blind spots by Goldmann perimetry that were not consistent with clinical findings; OKP showed normal sized blind spots.
Correspondence to: Mrs Timms.

Accepted 19 October 1989 
Clinical diagnoses and correlation with visual field assessment

\begin{tabular}{|c|c|c|c|c|c|c|c|}
\hline Case No & $\begin{array}{l}\text { Age } \\
\text { (years) }\end{array}$ & Sex & Disorder & Acuity & $\begin{array}{l}\text { Goldmann } \\
\text { fields }\end{array}$ & $\begin{array}{l}\text { Goldmann/clinical } \\
\text { correlation }\end{array}$ & $\begin{array}{l}\text { OKP/clinical } \\
\text { correlation }\end{array}$ \\
\hline 1 & 9 & $\mathbf{F}$ & Postencephalitis & $\begin{array}{l}\text { Right } 6 / 6 \\
\text { Left } 6 / 6\end{array}$ & $\begin{array}{l}\text { Peripheral constriction, } \\
\text { enlarged blind spots }\end{array}$ & Good & Moderate \\
\hline 2 & 11 & $\mathbf{F}$ & $\begin{array}{l}\text { Right temporal lobe } \\
\text { mass (after meningitis) }\end{array}$ & $\begin{array}{l}\text { Right } 6 / 18 \\
\text { Left } 6 / 18\end{array}$ & Gross constriction & Moderate & Moderate \\
\hline 3 & 8 & $\mathbf{F}$ & $\begin{array}{l}\text { Left lateral ventricle } \\
\text { choroid papilloma } \\
\text { (after surgery) }\end{array}$ & $\begin{array}{l}\text { Right } 6 / 6 \\
\text { Left } 6 / 6\end{array}$ & $\begin{array}{l}\text { Right homonymous } \\
\text { hemianopia }\end{array}$ & Good & Good \\
\hline 4 & 14 & $\mathbf{F}$ & Chiasmal glioma (after & Right 6/5 & Bitemporal hemianopia & Good & Good \\
\hline 5 & 14 & $\mathbf{M}$ & $\begin{array}{l}\text { Neurofibromatosis, optic } \\
\text { nerve glioma }\end{array}$ & $\begin{array}{l}\text { Right } 6 / 6 \\
\text { Left } 6 / 6\end{array}$ & Normal & Good & Good \\
\hline 6 & 8 & $M$ & Dominant optic atrophy & $\begin{array}{l}\text { Right } 6 / 18 \\
\text { Left } 6 / 60\end{array}$ & Peripheral constriction & Good & Poor \\
\hline 7 & 14 & $\mathbf{F}$ & Apert's syndrome & $\begin{array}{l}\text { Right } 6 / 6 \\
\text { Left } 6 / 12\end{array}$ & Tunnel fields & Poor & Good \\
\hline 8 & 8 & $\mathbf{M}$ & $\begin{array}{l}\text { Functional monocular } \\
\text { diplopia }\end{array}$ & $\begin{array}{l}\text { Right } 6 / 9 \\
\text { Left } 6 / 6\end{array}$ & Irregular constriction & Poor & Poor \\
\hline 9 & 11 & $\mathrm{~F}$ & $\begin{array}{l}\text { Facial haemangioma } \\
\text { with left hemisphere } \\
\text { infarct }\end{array}$ & $\begin{array}{l}\text { Right } 6 / 36 \\
\text { Left NPL }\end{array}$ & Spiralling constriction & Poor & Moderate \\
\hline 10 & 16 & $\mathbf{F}$ & $\begin{array}{l}\text { Neurofibromatosis, } \\
\text { optic nerve glioma }\end{array}$ & $\begin{array}{l}\text { Right } 6 / 5 \\
\text { Left } 6 / 5\end{array}$ & Normal & Good & Good \\
\hline 11 & 9 & $\mathbf{F}$ & $\begin{array}{l}\text { Neurofibromatosis, } \\
\text { chiasmal glioma }\end{array}$ & $\begin{array}{l}\text { Right } 6 / 5 \\
\text { Left } 6 / 5\end{array}$ & Normal & Good & Good \\
\hline 12 & 7 & $\mathbf{M}$ & Neurofibromatosis & $\begin{array}{l}\text { Right } 6 / 6 \\
\text { Left } 6 / 6\end{array}$ & $\begin{array}{l}\text { Failed to complete } \\
\text { either test }\end{array}$ & & \\
\hline 13 & 11 & $\mathbf{M}$ & $\begin{array}{l}\text { Craniopharyngioma } \\
\text { (after surgery) }\end{array}$ & $\begin{array}{l}\text { Right } 6 / 9 \\
\text { Left NPL }\end{array}$ & Hemianopia & Good & Good \\
\hline
\end{tabular}

NPL, no perception of light.
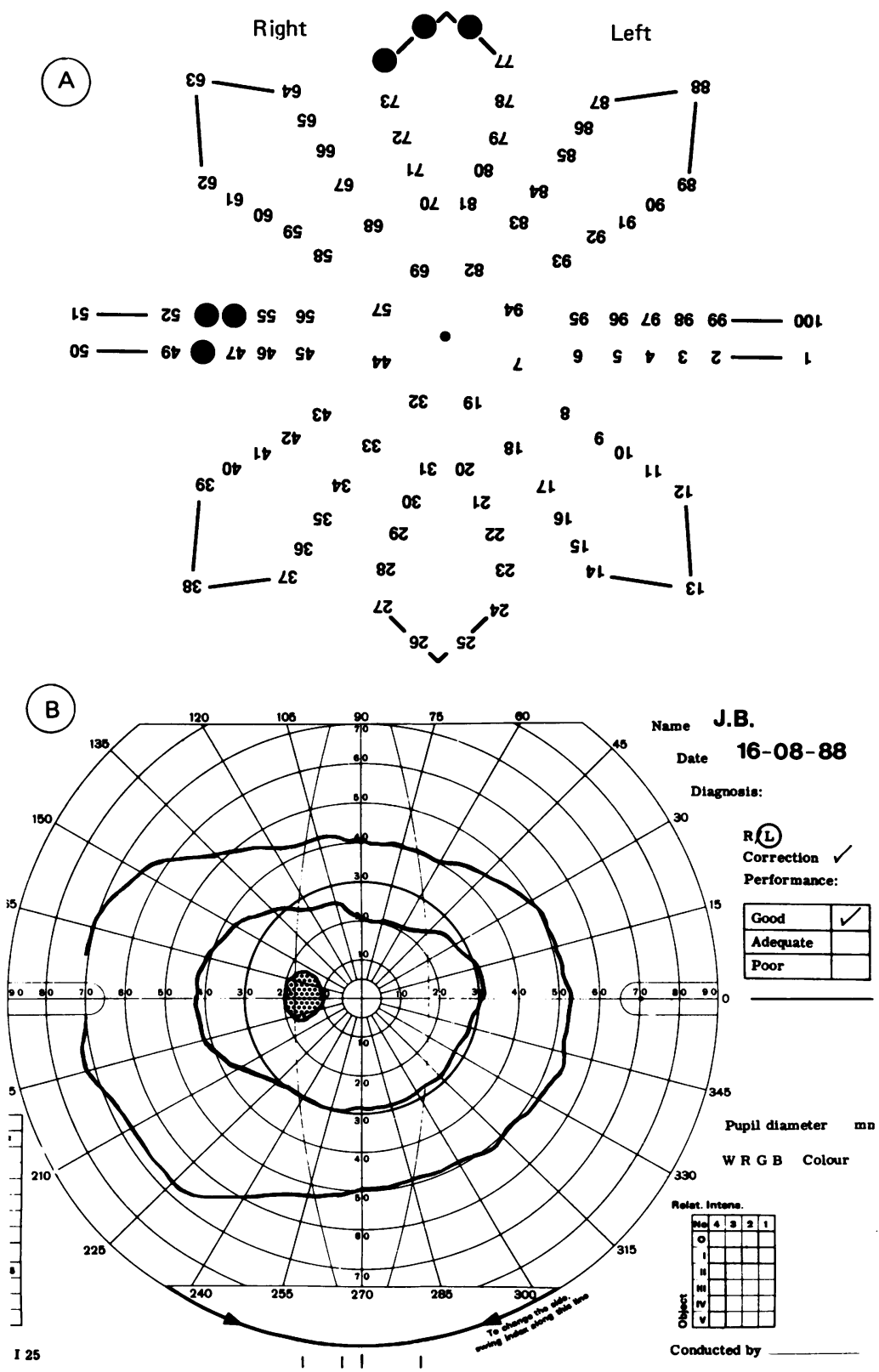

One child (case 7) showed constricted fields of less than 5 degrees by large and small targets by Goldmann assessment but OKP was normal; this correlated well with the clinical findings.

Two children (cases 8 and 9) had functional visual complaints diagnosed. Case 8 complained of double vision in one eye for which there was no apparent cause. Goldmann and OKP fields were abnormal and correlated poorly with each other. Case 9 suffered a left hemisphere infarct after embolisation of a facial haemangioma three years previously and presented with a sudden diminution of vision in her remaining seeing eye. There was no apparent cause for the recent deterioration in vision; confrontation fields at 1 metre and 6 metres showed tunnel vision and Goldmann fields showed spiralling. OKP, however, demonstrated a right hemianopic defect with peripheral constriction in this eye that was consistent with the clinical findings of mild optic atrophy and the appearance on computed tomography of a left hemisphere infarct.

Case 12 failed to complete either Goldmann or OKP field assessments because of emotional lability.

In summary, Goldmann and OKP field assessments were judged to correlate well in seven cases. In two cases OKP failed to demonstrate moderate peripheral constriction of fields. OKP was assessed as giving a more reliable assessment of field than Goldmann perimetry in two cases, one in a child with a normal field of vision and one in a child with hemianopia. One child with functional visual complaints had unreliable assessments by both techniques and one child failed to complete either test.

Figure 1 Normal central visual field and blind spot of the left eye of case 11 as determined by $(A) O K P$ and (B) Goldmann perimetry. The OKP field is inverted to ease comparison. 
(A)
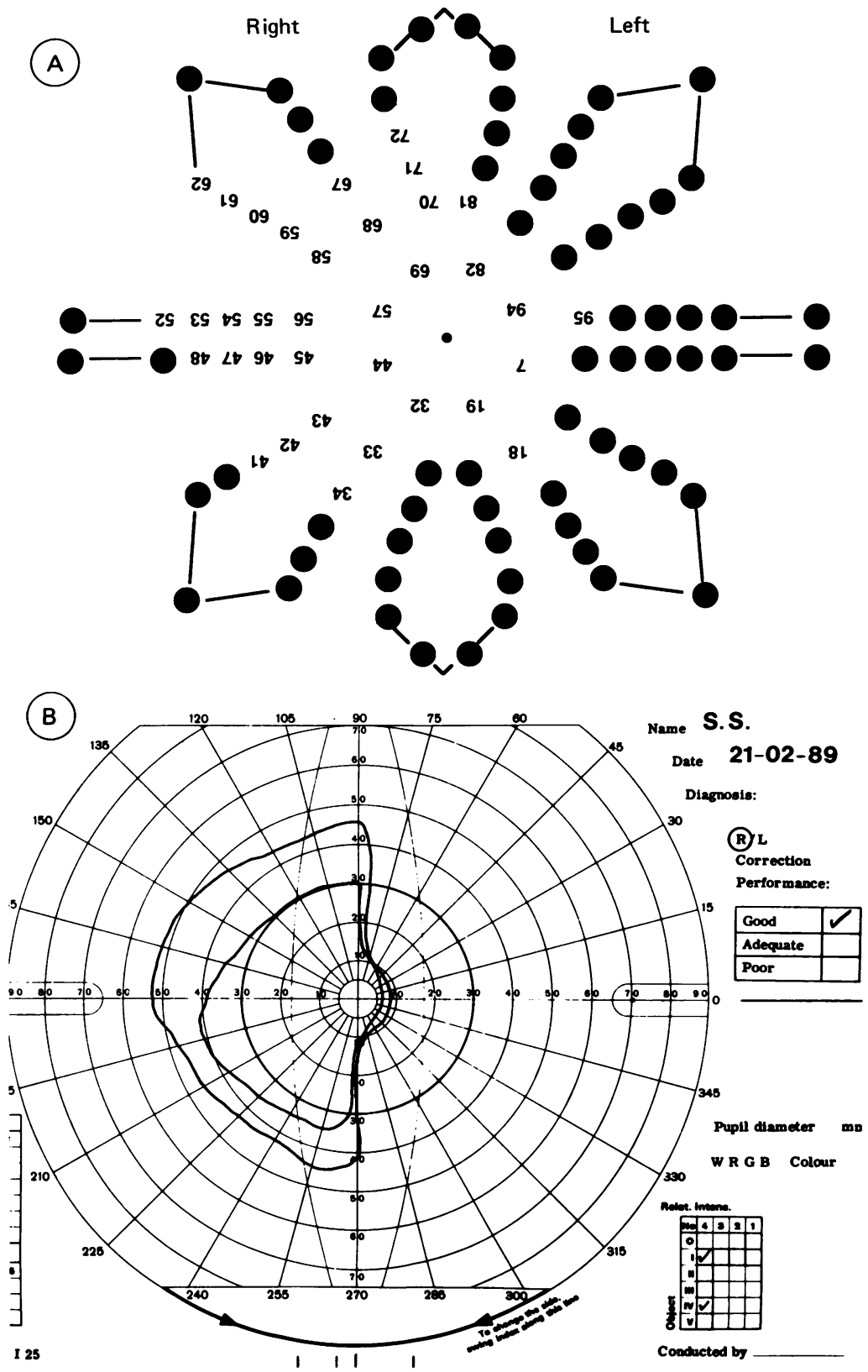

Figure 2 Case 13: hemianopia in the only seeing eye showing peripheral constriction; (A) OKP demonstrates macular sparing and $(B)$ Goldmann perimetry. The OKP field is inverted to ease comparison. be carried out in the normal clinical setting as the variation in ambient illumination does not affect the result. ${ }^{3}$ There are a reduction in the sources of fear and anxiety as the child and the observer are not remote. This proximity of the tester allows better assessment of the psychological response to the test and may give a better indication of the child's cooperation and the reliability of the test. Perhaps the greatest advantage of this method is that the child does not have to fixate one spot for any length of time.

Head movement and fidgeting are a difficulty with variability of distance from the chart so that a less accurate assessment of visual fields by OKP is likely when applied to children rather than adults. This can be seen in hemianopia where rotation of the child's head results in a field which transgresses the vertical meridians. Furthermore, there is a tendency for some children to strive for a perfect record in the test. This can be overcome by explanation that there may be some areas on the chart where it will not be possible to see both the number and the central dot together and that it is important for the child to find where these areas lie. A further drawback with this method is that it only examines the central 25 degrees of field.

In two cases in this study OKP was considered to give results which correlated better with the clinical findings than Goldmann perimetry. This, of course, begs the question 'which is the gold standard?' This can be difficult to ascertain in paediatric practice and no method currently available can be regarded as ideal. It is for this reason that OKP and Goldmann perimetry were not directly compared in isolation-both were also compared with the clinical impression. However, a situation where a direct comparison between two methods of perimetry may be of value is in the detection of functional field loss.

The present format of OKP possibly does not fulfil its true potential for the examination of children. The use of 100 numbered points could be modified to use fewer points as some children at the end of the test found it slightly tedious. The substitution of symbols for the numbers may be one adaptation that could prove useful in maintaining a child's attention. With these modifications, OKP could be of use in screening of visual fields in children. Further studies are required to assess the reliability of the test in longitudinal studies of changes in field defects.

We are indebted to Mr D Taylor and Dr B Damato for their advice on conducting this study. children, however, as it can easily frighten and alienate a child with subsequent breakdown of cooperation so necessary for a useful assessment of visual field. Inattentiveness to the fixation target is a major drawback when applying this test to children.

OKP has the advantages of simplicity, inexpensiveness, and portability. There is no requirement for a skilled perimetrist and it can 